\title{
ELECCIONES LEGISLATIVAS FRANCESAS, DE 26 DE MAYO Y 1 DE JUNIO DE 1997
}

CARMEN FERNÁNDEZ-MIRANDA CAMPOAMOR 
SUMARIO

I. INTROdUCCIÓN. II. La PRimera Vuelta electoral. III. La SEgunda VULETA EleCTORAL. IV. VALORACIÓN. 


\section{ELECCIONES LEGISLATIVAS FRANCESAS, DE 26 DE MAYO Y 1 DE JUNIO DE 1997}

POR

\section{CARMEN FERNÁNDEZ-MIRANDA CAMPOAMOR}

\section{INTRODUCCIÓN}

El 21 de abril de 1997, la Asamblea Nacional es disuelta por el Presidente de la República, Jacques Chirac, un año antes de finalizar la legislatura (marzo de 1998), en uso de la competencia que le atribuye el artículo 12 de la Constitución. La disolución de la Cámara es un poder propio del Jefe del Estado, no necesitado de refrendo, aunque sometido a determinadas cautelas:

a) La decisión ha de ser precedida de una consulta, obligatoria pero no vinculante, al Primer Ministro y a los Presidentes de ambas Cámaras del Parlamento. Prevención irrelevante en un equilibrio de poderes como el existente hasta el momento de la disolución, ya que la coincidencia de mayorías presidencial y parlamentaria sitúan al Presidente de la República, como líder de ambas, en efectivo protagonista de la dirección política.

b) La Constitución prohíbe que se decida tal disolución en tres supuestos concretos: durante el ejercicio de los poderes excepcionales establecidos en el artículo 16 de la Constitución, cuando se encuentre vacante la Presidencia de la República y asuma sus funciones interinamente el Presidente del Senado o, en su caso, el Gobierno; no antes de un año de la anterior disolución. Situaciones no existentes en este momento político concreto.

La disolución anticipada busca la última palabra del Cuerpo electoral a fin de lograr una Cámara que apoye la política presidencial, dada la diferente duración del los mandatos del Jefe del Estado -7 años-y de la Asamblea 
Nacional - 5 años-. En la $\vee$ República hubo, hasta la actual, cuatro disoluciones: dos decididas por el Presidente De Gaulle y dos por el Presidente Mitterrand; todas ellas esperadas y entendidas por la opinión pública, que apoyó mayoritariamente el deseo presidencial.

La disolución decidida por el Presidente Chirac, sin embargo, no fue entendida, ni justificada, ni respaldada por el electorado de forma mayoritaria. Veamos.

Jacques Chirac es elegido Presidente de la República el 7 de mayo de 1995; la Asamblea Nacional lo había sido el 21 y 28 de marzo de 1993, con unos resultados muy favorables a la coalición de centro-derecha, que logra 484 escaños de los 577 posibles, con una débil oposición de 70 escaños para el Partido Socialista y 23 escaños para el Partido Comunista.

Jacques Chirac, que en los dos años de Presidencia ha nombrado y mantenido al impopular Alain Juppé como Primer Ministro, disuelve la Asamblea Nacional favorable, pretendiendo del electorado una nueva Cámara con un reparto de poder similar, que respalde la política presidencial en los cinco años que le quedan de mandato. La decisión política se apoya, al menos, en dos razones. En primer lugar, el convencimiento de que el Partido Socialista no ha podido recuperarse tras la debacle electoral de 1993. En segundo lugar, la seguridad de que la opinión pública comprenderá la exigencia de máxima estabilidad, lejos de la tan temida cohabitación política, para afrontar —con fuerza y una sola voz- los próximos e importantes retos europeos. Con Alain Juppé como líder, la coalición presidencial inicia la campaña electoral segura de su triunfo en las urnas, según anuncian los primeros sondeos.

Las elecciones a la Asamblea Nacional se celebran los días 26 de mayo y 1 de junio de 1997 para cubrir 577 escaños, con un mandato de cinco años. El sistema de escrutinio es uninominal mayoritario, a dos vueltas (salvo los representantes de ultramar elegidos a una vuelta). En la primera vence el candidato que haya alcanzado la mayoría absoluta; a la segunda vuelta solo pueden optar aquellos que hayan logrado un número de votos igual al $12,5 \%$ de los electores de la circunscripción; si no se da este caso, se presentarán los dos candidatos más votados. Serán elegidos quienes logren la mayoría simple.

\section{LA PRIMERA VUELTA ELECTORAL: 26 DE MAYO DE 1997}

Principales partidos y coaliciones, con sus lideres. 
Coalición de Centro-Derecha: RPR (Agrupación para la República) y UDF (Unión para la Democracia Francesa). Alain Juppé).

Partido Socialista (PS). Lionel Jospin.

Partido Comunista $(P C)$. Robert Hue

Los Verdes. Dominique Voynet

Frente Nacional( FN). Jean Marie Le Pen

La campaña electoral, iniciada el 5 de mayo, muestra el desconcierto de la opinión pública ante una disolución inesperada, que entiende busca esencialmente la comodidad política del Presidente y no el interés de Francia.

Alain Juppé, como candidato de la Coalición de centro-derecha, defiende lo que ha sido eje de su política, muy contestada por las fuerzas sociales: rigor presupuestario, reducción del gasto público, logro de la convergencia como principal valor. Dándole todo el apoyo, se implica directamente en la campaña el Presidente Chirac; si bien todos los Presidentes de la V República intervinieron en la campaña electoral a favor de sus respectivos partidos, ninguno lo hizo con el dramatismo del actual: en una carta abierta a los franceses ante la amenaza de una cohabitación con la izquierda, manifestada en los últimos sondeos de opinión. Como un nuevo De Gaulle, pide respuesta al electorado para el mantenimiento de "la grandeza» de Francia en Europa, que necesita una sola voz ante el reto de la convergencia, y la moneda única, de la reforma de las instituciones de la Unión y de la reforma de la OTAN: "preciso la fuerza política necesaria para poder defender los intereses de Francia con motivo de los próximos e importantes plazos Europeos...».

Lionel Jospin, envía al electorado un mensaje moderado: su partido, que ha logrado el apoyo y alianza de la mayor parte de la izquierda, no rechaza la cohabitación con el Presidente de la República ya que, entiende, comparten lo esencial de la construcción Europea y aportaría a Francia la defensa del Estado social frente al liberalismo extremo de Juppé; pese a su mensaje positivo, el electorado percibe numerosos problemas en el entendimiento de los socialistas con sus aliados comunistas y ecologistas, ya que frente a la convergencia mantienen posiciones enfrentadas.

Por último, el lider ultraderechista Le Pen defiende su permanente mensaje: antieuropeo, xenófobo y disgregador; pide el voto para que en la nueva Asamblea Nacional se oiga «la voz de la fuerza».

El día 26 de mayo se celebra la primera vuelta de las elecciones, con una gran incertidumbre; los últimos sondeos son favorables a la izquierda y anunciadores de una gran abstención. 


\section{RESULTADOS OFICIALES DE LOS PRINCIPALES PARTIDOS $Y$ COALICIONES \\ (sin los datos de Martinica, Guadalupe y Guayana francesa)}

\begin{tabular}{ccr}
\hline $\begin{array}{c}\text { Abstención: } 31,69 \% . \\
\text { Siglas }\end{array}$ & votos & $\%$ \\
\hline UDF & 3.600 .473 & $14,34 \%$ \\
RPR & 3.914 .417 & $15,59 \%$ \\
Diversas derechas & 1.637 .340 & $6,52 \%$ \\
\hline PS & 5.942 .696 & $23,67 \%$ \\
PC & 2.506 .682 & $9,98 \%$ \\
Ecologistas & 1.724 .122 & $6,86 \%$ \\
\hline FN & 3.782 .427 & $15,06 \%$ \\
Otras izquierdas & 1.636 .243 & $6,50 \%$ \\
Otras extrema derecha & 26.438 & $0,10 \%$ \\
\hline
\end{tabular}

$\%$ Coalición de centro-derecha: $36,45 \%$

$\%$ Alianza de izquierdas: $40,55 \%$

\section{LA SEGUNDA VUELTA ELECTORAL: 1 DE JUNIO DE 1997}

La prensa nacional e internacional se hace eco del gran error político del Presidente al disolver la Asamblea por su propio interés y pone de relieve como, más que un triunfo de la izquierda, hay que señalar una derrota de la derecha y de la política llevada a cabo en los dos últimos años. La consecuencia inmediata es la dimisión del Primer Ministro Juppé, rasgo sin precedente en la historia de la $V$ República, a fin de que la coalición pueda presentar al electorado una nueva imagen esperanzadora; se recurre al Presidente de la Asamblea Nacional disuelta, Philippe Séguin, gaullista de fuerte sensibilidad social y muy critico con Maastricht; la coalición presidencial siente la necesidad apremiante de llegar a los numerosos abstencionistas y lograr el apoyo de una parte de los votantes de Le Pen quien, reforzado por los buenos resultados obtenidos, pide nuevamente el voto para sus candidatos, sin admitir ningún pacto, mientras solicita la dimisión del Presidente Chirac.

Contabilizando todos los votos emitidos, un $62,19 \%$ de los electores han rechazado la política presidencial. 
El día 27 de mayo, el Presidente Chirac participa nuevamente en la campaña asumiendo, en opinión de la mayoría de los comentaristas políti$\cos$, un riesgo sin precedente; mantiene su inicial mensaje pero sin la agresividad anterior, sin rechazar una posible cohabitación con la izquierda: pide al electorado que «permita la existencia de una mayoría parlamentaria que no fragilice la construcción Europea». La Coalición de centro derecha, a su vez, finaliza la campaña con palabras catastrofistas para la Unión si triunfa la alianza de izquierda. El Ex-Presidente Giscard D'Estaing publica un artículo en Le Figaro, el 30 de mayo, en la misma linea: «... Aunque Chirac y Jospin se respeten, cada uno intentará vencer al otro. La cohabitación será un régimen bicéfalo con dos dirigentes antagonistas».

Lionel Jospin, por su parte, mantiene el mensaje moderado y pretende dejar claros sus objetivos: el cumplimiento gradual de sus promesas electorales; su europeísmo probado y la exigencia a sus aliados del respeto a los compromisos asumidos con la Unión, si quieren participar en un posible Gobierno; finalmente, su convencimiento de que la cohabitación será buena para Francia porque la izquierda defenderá en Europa las conquistas del Estado social. En suma, si a Maastricht pero si a la necesidad de «reinterpretarlo».

Robert Hue responde a Lionel Jospin y a sus votantes: mantiene su compromiso de pertenecer a la nueva mayoría, pero solo entrará en un hipotético gobierno si logra «las respuestas suficientes».

Finalmente, el lider del Frente Nacional pide a sus simpatizantes que mantengan su voto para castigar a la derecha; que se opongan a todos los que defienden intereses ajenos a Francia: «...la Europa de Maastricht sólo pretende la disolución de Francia....anular nuestra cultura...nuestra economía...nuestras costumbres...».

Como nota a destacar por las consecuencias que pueda tener, el día anterior a la votación el diario Le Parisien desafía las normas vigentes publicando un sondeo solicitado por el diario suizo La Tribune de Geneve al Instituto CSA. Los datos son los siguientes:

Coalición de Centro-Derecha y aliados 260 escaños.

PS y aliados: 283.

Partido Comunista:32.

Frente Nacional: 1 escaño.

Otras formaciones: 1 escaño. 
El artículo 11 de la Ley Electoral de 19 de julio de 1977, prohíbe la publicación, difusión y comentario de cualquier sondeo de opinión durante la semana que precede a cada vuelta electoral; el artículo 12, sanciona con una multa de un máximo de $\mathbf{5 0 0 . 0 0 0}$ francos a quienes vulneren la norma citada.

Pese a lo dicho el periódico francés publica la última encuesta, consciente de estar realizando un acto ilegal y sin precedentes, que justifica con los siguientes argumentos.

a) La defensa del derecho a la información de los ciudadanos ya que un sondeo de opinión hace posible apreciar una situación política en un momento concreto, por lo que la información debe circular libremente.

b) La defensa del principio de igualdad, ya que el derecho a la información corresponde a todos los ciudadanos; con los adelantos técnicos actuales -canales electrónicos, internet, minitel...- solo unos pocos pueden acceder a aquella, por lo que la norma prohibitiva ha devenido caduca, inaplicable, injusta y antidemocrática.

Finalmente, el Tratado de Roma garantiza la libre circulación de la información; las elecciones francesas interesan a sus propios ciudadanos y, también, a los ciudadanos de la Unión.

En esta ocasión las urnas han confirmado los sondeos, con un claro triunfo de Lionel Jospin y sus aliados.

RESULTADOS OFICIALES, con mención de los principales partidos

Abstención: $28,6 \%$.

PS:

PC:

Los Verdes:

Diversos de Izquierda:

RPR-UDF:

Diversas derechas:

FN:

Otras Izquierdas:

Mayoría absoluta (de 577 escaños): 289 escaños.
240 escaños
38 escaños
7 escaños
21 escaños

243 escaños

14 escaños

1 escaño

13 escaños 


\section{VALORACIÓN}

- A modo de resumen de los resultados electorales, hay que resaltar, en primer lugar, el triunfo de la alianza de izquierdas, liderada por el socialista Lionel Jospin, respaldada por parte de la abstención de la primera vuelta (que ha disminuido en más de tres puntos); sin triunfalismo, consciente de las enormes dificultades par lograr un gobierno eficaz, Jospin confirma sus intenciones de lograr una cohabitación eficaz y de "reorientar Europa»: reinterpretar Maastricht en clave social.

Fruto de la alianza con Jospin, comunistas y ecologistas han podido mantener sus candidatos y evitar el voto útil de última hora; ello ha supuesto un notable aumento de representación del Partido Comunista, que le convierte en esencial para mantener la estabilidad política del nuevo Gobierno; a su vez, la entrada de Los Verdes en la Asamblea Francesa. Como ha dicho Dominique Voynet, «éxito de la alianza rosa, roja y verde».

En segundo lugar, derrota personal del Presidente Chirac quien, con una decisión política a todas luces inoportuna, ha llevado al desastre a su propia coalición, en un momento político especialmente importante para Francia y para toda la Unión Europea. La Coalición de Centro-Derecha se desmorona como consecuencia de la derrota y de sus contradicciones internas; se oyen numerosas voces que hablan de «refundición» y son varios los líderes que pretenden ejecutarla: Philippe Séguin, Edouard Balladur, Charles Pasqua, Francois Leotard, Alain Juppé...

- Desde 1981, en cada convocatoria electoral, Francia ha dado un giro total, dando su confianza a la oposición; es decir, ha votado mayoritariamente «contra» el Gobierno de turno. Ello significa, por un lado, la importancia creciente de la buena gestión, muy por encima de las ideologías políticas; en segundo lugar, una permanente búsqueda de norte ante los cruciales cambios del último tercio de siglo; Charles Pasqua lo interpreta como "una confirmación del temor y las dudas de Francia ante el futuro».

- Como consecuencia política inminente en el vecino pais, hay que señalar el cambio en el debate sobre la Unión Europea, cambio apuntado ya en las recientes elecciones británicas con el triunfo del nuevo laborismo de Tony Blair: la Unión Europea ha de primar ja solución de los problemas inmediatos del ciudadano y la defensa de las conquistas sociales. Si bien es una decisión de un país concreto, ha de repercutir necesariamente en todos los Estados miembros de la Unión (de los que, en este momento, sólo dos España y Alemania- tienen Gobiernos de derechas; en Portugal y Grecia 
gobierna el Partido Socialista en solitario y en el resto de la Europa comunitaria en coalición).

El día 3 de junio, el Presidente J.Chirac encarga a Lionel Jospin la formación de un nuevo Gobierno; ello supone el inicio de la tan temida, y larga, cohabitación política entre un Presidente conservador y un Primer Ministro socialista, que precisa el apoyo de otras formaciones. Lo contrario de las dos experiencias anteriores (1986-88;1993-95).

El temor del Presidente Chirac a este reparto de poder no es gratuito; sabe, por propia experiencia, que un Primer Ministro, apoyado por la Asamblea Nacional, puede imponer su política al Presidente de la República quien, en esta coyuntura, habrá de replegarse hacia la posición clásica de Jefe de Estado parlamentario, representante de la Nación y garante de su unidad y permanencia. Es decir, el Gobierno, con el apoyo de una mayoría parlamentaria opuesta a la presidencial, será el centro de impulsión y la politica que se lleve a cabo será la del Primer Ministro y no la del Presidente de la República.

El Presidente Chirac ha de recordar el permanente duelo entablado con el Presidente Mitterrand en la primera cohabitación política; situación que, por la debilidad política de éste, no se dio en la segunda experiencia. Qué modelo va a elegir el combativo Jacques Chirac, tras el rechazo electoral sufrido, es aún una incógnita.

Datos oficiales proporcionados por el Ministerio del Interior francés.

Prensa consultada (5 de mayo-3 de junio de 1997):

Le Monde. Le Figaro. Le Parisien. EI País. ABC. 